\title{
Changes in User Needs and Behavior and Analysis of Library Service Ability
}

\author{
Jianfei Hu
}

Library, University of Jinan, Jinan, Shandong, 250022

Keywords: user needs; behavior; library service ability

\begin{abstract}
User needs are one of the most active and important elements in library work. It is a prerequisite for the existence and development of library information services. User needs determine user behavior and directly affect the content of library information services, becoming a contemporary library. With the inherent drive of development, the ultimate goal of library services is to meet the needs of users. Under the digital network environment, due to the significant changes in the user's information environment, the user's needs presented new features, which in turn brought about changes in the behavior of traditional library information users, and also prompted changes in the service orientation of modern libraries. How to adapt to the development of the situation, pay attention to and meet the new and ever-increasing demands of users, has become a key issue in library service innovation today.
\end{abstract}

\section{Introduction}

Traditional information transmission in libraries is based on the borrowing of books in the library and the borrowing of books between libraries. This method is limited by the time factor, geographical factor and personnel factor, which makes the information transmission range not wide and the depth of information transmission limited. With the development of network technology and the popularization of computer use, the information of the library can be accessed on a computer, and even the electronic resources of libraries that are open to the general public all over the world can be accessed. All new library books can be delivered via the Internet. The library information service realizes a cross-time, cross-space, and cross-regional model. The launch of R-LEARNING (Electronic Learning) and E-SCIENCE (Digital Research) on the learning exchange platform was quickly favored by young readers and researchers. Under the digital network environment, e-learning and the sharing of e-book literature resources is a breakthrough reform of modern education. Most of the domestic research universities now provide students with interactive learning and communication platforms. Students can use computers to access library e-resources or e-mail application resources, waiting for the librarian's e-mail reply to the required resources.

The popularization of sub-learning methods has brought about a reorganization of the information service market environment and a new model. The rapid rise of new resource providers represented by Google, Amazon (Amazon Bookstore) and Randon-House (Landeng House) internationally; the development of domestic resources such as Baidu Library, Douding Library, and paid resource forums; learning exchange platforms and With the rise of technology forums, information readers have access to and exchange information in real time, these factors have affected the traditional library service areas. This has brought great competition and threats to traditional libraries.

\section{New Features of User Needs}

Users want the library to provide one stop shopping's "one-stop" seamless resources and services. Library users want the library to provide detailed and precise book navigation, preferably using indoor positioning technology, to provide navigation lines for books. At the same time, the user also hopes that the library will provide training in the retrieval methods for books and periodical resources so that users can accurately retrieve the required resources at the fastest speed. Provides accurate guidance for retrieval of digital retrieval resources in a distributed heterogeneous 
environment. The application of the library comes from all walks of life. The information resources needed involve multiple disciplines and industries. With the development of science and technology, discipline classification is more meticulous, and marginal science and cross science are emerging in large numbers, so users need to be professional in the process of retrieval. The knowledge service. This requires the library staff to accurately classify the library resources and journal resources, and provide professional fuzzy queries while providing accurate indexes. Such a search requires the professional technical personnel of each professional to summarize and categorize the keywords. This work is relatively easy to implement in a research university. The current popular web portals, such as Weibo, various news website portals, and shopping websites, are dedicated to providing customers with better personalized needs and providing more comfortable browsing services. Similarly, in the information management system of library management, the library needs to provide processed and targeted personalized information services. For example, the development of library-specific applications for the reader to create a corresponding user name, record the user's access to historical data, according to the classification of historical data, estimate the reader's professional and entertainment direction, regularly regularly push the reader to the appropriate professional knowledge and interest information. Information readers may also hope that the library can provide learning exchange platforms such as Baidu Post Bar and Xiaomucha Scientific Research Forum. The library can push communication platforms and communication groups according to the registered subjects' search and search subjects and interest contents.

\section{New Features of User Behavior}

The ultimate goal of library services is to meet the needs of users. The development history of libraries has long proved that user needs are the internal driving force for the existence and development of libraries. The profound changes in the information environment have brought new features to the user's needs. Specifically, under the digital environment of the Internet, the user's demand for information resources is no longer limited to a single type of printing resource, but to a multimedia transformation. The resource acquisition channel is no longer limited to the library's traditional document borrowing service. Instead, it uses resources such as computer networks and databases to obtain resources. The infinite richness of information resources, on the one hand, makes up for the user's lack of traditional library resource requirements; on the other hand, it also brings great confusion to users. Users want the library to provide integrated navigation of resources and provide specialized user search skills training. Especially for digital resources in distributed heterogeneous environments, users want libraries to provide "One-stop Shopping" seamless resources. and service.

With the continuous development of science and technology, a large number of cross-disciplinary and marginal disciplines have emerged, and user information needs involve multiple disciplines and industries. At the same time, what the user needs is not only general and descriptive information, but also emphasizes specific information. The user hopes that the library can provide systematic and refined information, provide a direct infiltration to the knowledge unit, and can directly solve the user. Practical issues of knowledge services. Compared with traditional information services, which focus on the acquisition and transmission of information resources, knowledge services are content-oriented services, solution-oriented solutions, and services that solve the entire process of users. They are value-added services.

In the network environment, users no longer satisfy general information consulting services. Users have switched from "passive recipients" of services to "active choicers", and they are more likely to get personalized information services tailored for themselves. . They have their own clear information needs and user personality. They need the library to provide processed, specific, and targeted information. Personalized information requirements call for personalized information services. This requires the library to establish an interactive information service mechanism with users. In the process of interacting with users, collect interest from users and fully tap user requirements through personalization. Customize and promote to meet their needs. At the same time, in the process of obtaining information, users hope to communicate and communicate with the 
librarians and get help, for example, through online interactive question and answer, online reference consultation, BBS, blog (Blog) to communicate and communicate. The further maturity of digital library technology, especially technologies such as artificial intelligence, machine learning, information retrieval, information recommendation, and information filtering, has provided an opportunity for libraries to implement interactive personalized services.

In the network environment, the rhythm of people's work and life is greatly accelerated, and the transformation of network information organization, transmission, and communication methods promotes knowledge information activities to exhibit high-speed, large-scale, and high-efficiency characteristics. Knowledge aging speeds up and information aging becomes increasingly Enhanced. The core resource of the Internet age is information and its knowledge of systematic information. For information users, information is increasingly becoming an indispensable resource. The demand of users for information has become the first need for their survival and development. Users need continuous access to information and updated knowledge to keep up with the times. For the library's services, users hope to get the services of the library anytime, anywhere. Users need all the latest knowledge information. They don't want to wait, they have too late to wait.

\section{Orientation of Library Service}

Library service orientation is a concept introduced from the economic field. In the economic field, service orientation refers to the tendency of service personnel to meet customer needs in the environment. It means that the company and its employees give priority to the interests of customers, meet the needs of customers through quality services, and develop cooperation between customers and customers. relationship. At the library level, service orientation is a philosophy and atmosphere that permeates the daily activities, business, and disciplines of the library. The concept and atmosphere requirement, whether it is the planning and design of library service projects, the choice of service methods, or the operational mechanism and management mechanism of service projects, must be provided from the most effective, most reliable, and sustainable To ensure the user's desired perspective, the user can review whether the information needs can be satisfied, whether the degree of satisfaction has been significantly improved, and whether the degree of satisfaction is faster and the benefits are high, so that the library and the user Establish a cooperative, win-win relationship. The service orientation of the library is a manifestation of the humanistic spirit of the library. It requires all work of the library to be user-centered, and to observe, examine, and realize the value and purpose of its own service from the standpoint of the user.

Corresponding to service orientation is the traditional library's resource orientation or book orientation. Traditional libraries are more concerned with information objects (collection resources) than information users (readers). Due to the traditional "resource-oriented" library "serving centered on collections", it is easy to cause disadvantages such as duplicate construction of the collection, single collection structure, low utilization rate, small service scope, low service level, and poor service results. In the 21st century, the focus of library work will shift from "book-based" to "people-based", the business focus will shift from the second line to the front line, and the service focus will shift from general service to reference service. The realization of the shift from "book-based" to "people-based" is very important to be "user-centered". Requires the library to closely integrate information users, information resources and information technology, focusing on user structure, reading trends, the number and proportion of various groups, the frequency and manner of using libraries, the level and level of satisfaction of services, and possible future development. Parameters such as change, continuous collection of user data, in-depth study of user information requirements, establishment of clear and orderly user feedback channels, and scientific, feasible, systematic evaluation indicators to objectively and accurately reflect and evaluate the status of library service operations And efficiency, indicating the links and projects that need to be improved, and tailoring service measures to expand and upgrade library information services and knowledge services. 


\section{Conclusion}

Corresponding to service orientation is the traditional library's resource orientation or book orientation. Traditional libraries are more concerned with information objects (collection resources) than information users (readers). Due to the traditional "resource-oriented" library "serving centered on collections", it is easy to cause disadvantages such as duplicate construction of the collection, single collection structure, low utilization rate, small service scope, low service level, and poor service results. In the 21st century, the focus of library work will shift from "book-based" to "people-based", the business focus will shift from the second line to the front line, and the service focus will shift from general service to reference service.The realization of the shift from "book-based" to "people-based" is very important to be "user-centered". Requires the library to closely integrate information users, information resources and information technology, focusing on user structure, reading trends, the number and proportion of various groups, the frequency and manner of using libraries, the level and level of satisfaction of services, and possible future development. Parameters such as change, continuous collection of user data, in-depth study of user information requirements, establishment of clear and orderly user feedback channels, and scientific, feasible, systematic evaluation indicators to objectively and accurately reflect and evaluate the status of library service operations And efficiency, indicating the links and projects that need to be improved, and tailoring service measures to expand and upgrade library information services and knowledge services.

\section{References}

[1] Huang Haiyan, Huang Lianqing. Service Orientation and Library Value Reengineering [J]. Journal of Foshan University of Science and Technology: Social Science Edition, 2004, (6): 88-90.

[2] Chang Wei. To build a new model of information service under the digital network environment [J]. Library and Information Technology, 20016, (2): 77-80.

[3] Chang Wei. Building a New Model of Information Service in Institutes under Digital Network Environment [J]. Library and Information Technology, 2006, (2):77-80.

[4] Wu Jianzhong. New Theory of 21st Century Library [M]. Shanghai: Shanghai Science and Technology Literature Publishing House, 2008.

[5] Huang Haiyan, Huang Lianqing. Service Orientation and Library Value Reengineering [J]. Journal of Foshan University: Social Science Edition, 2014, (6): 88-90. 